\title{
Torque Ripple Minimization for a Permanent Magnet Synchronous Motor Using a Modified Quasi-Z-Source Inverter
}

\author{
Hamid Mahmoudi ( ${ }^{(0)}$, Mohsen Aleenejad, Member, IEEE, and Reza Ahmadi ${ }^{\circledR}$, Member, IEEE
}

\begin{abstract}
This paper presents a torque ripple minimization method for a permanent magnet synchronous motor (PMSM) drive system that utilizes a modified quasi-Z-source (qZS) inverter. The proposed modified qZS network is designed by adding an extra switching device to the conventional qZS topology and provides a wider range of capabilities for inverter input voltage control, e.g., both step-up and step-down operations. It also allows for modification of the traditional switching sequence selection scheme when using the space vector modulation (SVM) for switching. The provided flexibilities are leveraged to develop a control system that minimizes the torque ripples during PMSM operation while satisfying conventional control objectives such as shaft speed control. The control system is comprised of an input voltage optimization subsystem with the goal of torque ripple minimization, which provides the reference for a cascaded modulated model predictive control subsystem for the modified qZS network control, and a motor side predictive control subsystem. The control system employs a new switching sequence selection scheme for SVM modulation to further reduce PMSM torque ripples. Experimental results are provided to validate the theoretical outcomes.
\end{abstract}

Index Terms-Model predictive control (MPC), permanent magnet synchronous motor (PMSM), quasi-Z-source (qZS) network, space vector modulation (SVM).

\section{INTRODUCTION}

$\mathbf{S}$ INCE its introduction [1], the concept of Z-source network has pioneered a new research area in the field of power electronics. Although the main function of a Z-source network is to help overcome some of the operational barriers faced by traditional voltage source and current source inverters [2], researchers were quick to discover many other interesting applications for Z-source networks in a wide verity of power conversion systems [3]. Utilization of Z-source inverters in electric motor drive systems has become an appealing research area recently due to a myriad of advantages that the Z-source networks provide for drive systems, such as extending the output voltage

Manuscript received September 8, 2017; revised January 26, 2018 and April 9, 2018; accepted June 22, 2018. Date of publication July 3, 2018; date of current version February 20, 2019. Recommended for publication by Associate Editor A. Mertens. (Corresponding author: Reza Ahmadi.)

H. Mahmoudi and R. Ahmadi are with the Department of Electrical Engineering and Computer Science, University of Kansas, Lawrence, KS 66045 USA (e-mail: Mahmoudi@ku.edu; ahmadi@ku.edu).

M. Aleenejad is with the Department of Electrical and Computer Engineering, New York University, Brooklyn, NY 11201 USA (e-mail: Aleenejad@nyu.edu).

Color versions of one or more of the figures in this paper are available online at http://ieeexplore.ieee.org.

Digital Object Identifier 10.1109/TPEL.2018.2852753 of the inverter, preventing voltage sags, reducing the inrush and harmonic currents from the diode rectifier, and improving the reliability of the inverter against miss-gating of switching devices [4], [5]. Therefore, researchers have been focusing recently on improving the operation of motor drive systems using Z-source networks. Most relevant to the work presented in this paper, in [6] a control strategy for electric traction systems based on bidirectional Z-source inverters has been proposed. In [7], Li et al. have proposed a method to reduce the commutation torque ripple of a Z-source inverter fed brushless dc motor by regulating the shoot-through vector and active vector duty cycles. Also in [8], authors have proposed a technique for dynamic commutation torque ripple reduction of a quasi-Z-source (qZS) inverter fed brushless dc motor by providing enough voltage at commutation interval using the qZS network when the motor is operating at high speeds.

Permanent magnet synchronous motors (PMSMs) are replacing induction machines in industry due to their high efficiency, low inertia (which makes them attractive for servo applications), high power density, and reliability. However, the issue of proper control of PMSMs while fully taking advantage of their capabilities to achieve certain desired performance criteria is still an open problem. Torque ripple is one of the issues that affects the performance of PMSMs. The torque ripple primarily affects the performance and accuracy of position control systems for PMSMs, preventing these machines to be utilized in applications that require very accurate position control, e.g., robotic systems [9]. The torque ripples also induce undesired mechanical vibrations and acoustic noise in PMSMs [10]. In this paper, a new PMSM drive system with a modified qZS network is proposed to reduce the torque ripples during operation.

A qZS inverter is employed in this work because it features superior characteristics such as continuous input current and joint earthing of the dc source and the dc-link bus [11]. Moreover, the voltage of one of the qZS network capacitors is significantly less than its counterpart in a Z-source network, resulting in smaller passive components size compared to a conventional Z-source network [12], [13]. The qZS network is also suitable for high power applications such as multilevel converters [14], [15], as well as photovoltaic systems [16], [17]. However, since the conventional qZS network can only increase the input voltage [18], it has been modified in this paper by adding a switching device to its topology, enabling it to decrease the input voltage as well. This modified qZS network provides great flexibility 
for controlling the input voltage of the inverter and manipulating the switching sequence while using space vector modulation (SVM) for switching. Both properties are leveraged in this work for torque ripple reduction. First, a method for finding an optimum value for the input voltage of the inverter that minimizes the torque ripples in a PMSM is developed. Although the SVM method can generate voltages lower than the qZS input voltage using modulation, the developed method also requires the inverter input voltage itself to be lower than the qZS input voltage in some operating conditions to effectively reduce the torque ripple. The modified qZS network can generate voltage on the input of the inverter, which could be less than the qZS input voltage or more than the qZS input voltage (step-down or step-up operations). Second, the shoot-through states for the qZS network are leveraged in this work to develop a new switching sequence selection method for SVM that leads to even further torque ripple reduction at a certain optimum inverter input voltage.

Model predictive control (MPC) technique is gaining momentum as a new control approach for qZS converters due to its considerable benefits such as simple implementation, flexibility, and incorporation of nonlinearities in the cost function [19], [20]. Therefore, in this work, a cascaded control system based on MPC has been proposed to control the modified qZS network. The employed modulated model predictive controller (MMPC) can provide fast and stable response when controlling the modified qZS network [21]. The proposed controller not only retains all the mentioned benefits of the MPC, but also uses a modulation technique to accurately follow the current reference of the inductor of qZS and thus results in a fixed switching frequency. On the motor side, a predictive controller has been used to control the PMSM. This predictive controller provides similar dynamic performance and better steady-state response compared to MPC for PMSM control. This method uses the motor's discrete dynamic model to predict voltage references and then converts them into corresponding switching commands using SVM [22].

The paper is organized as follows. In Section II, the system under study is presented and the SVM method is briefly reviewed. In Section III, the proposed control system with torque ripple minimization capability is presented. Section IV verifies the outcome of the proposed method using experimental results. Section V concludes this paper.

\section{GROUNDWORKS}

Fig. 1 illustrates the system under study and its associated proposed control system. This system is comprised of the proposed modified qZS network connected to a three-phase two-level inverter. The inverter feeds a PMSM and the motor operation is controlled using the proposed method in this paper to minimize the ripples of the delivered torque.

\section{A. PMSM Model}

The proposed method in this paper uses the PMSM's model in a rotor reference frame. The $d$ - and $q$-axes equations as well as the electrical torque and motor shaft dynamic equations in

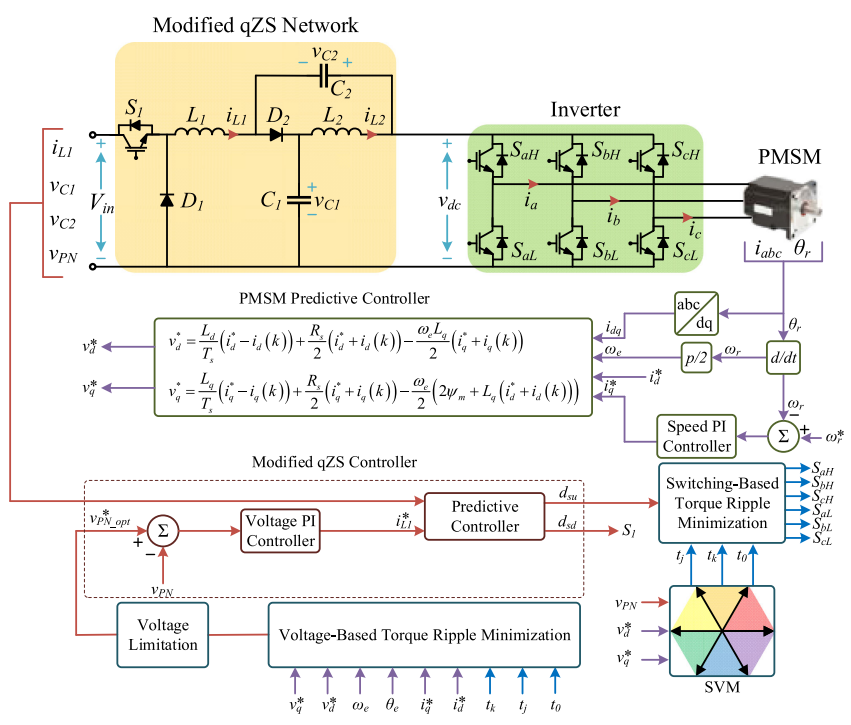

Fig. 1. Modified qZS inverter and the block diagram of the proposed control system for PMSM torque ripple reduction.

rotor reference frame are [23]

$$
\begin{aligned}
v_{d} & =R_{s} i_{d}+L_{d} \frac{d i_{d}}{d t}-\omega_{e} L_{q} i_{q} \\
v_{q} & =R_{s} i_{q}+L_{q} \frac{d i_{q}}{d t}+\omega_{e}\left(L_{d} i_{d}+\psi_{m}\right) \\
T_{e} & =\frac{3}{2} p \psi_{m} i_{q} \\
J \frac{d \omega_{m}}{d t}+B \omega_{m} & =T_{e}-T_{l}
\end{aligned}
$$

where $\psi_{m}, i_{d}, i_{q}, v_{d}, v_{q}, R_{s}, L_{d}, L_{q}$, and $\omega_{e}$ are, respectively, the amplitude of rotor magnetic flux linkage, $d$ - and $q$-axes stator currents, $d$ - and $q$-axes stator voltages, stator resistance, $d$ - and $q$-axes stator inductances, and rotor electrical angular speed. Also, $\omega_{m}, T_{l}, J$, and $B$ denote the rotor shaft's angular mechanical speed, load torque, mechanical inertia, and the friction coefficient, respectively. This study considers the PMSM to have surface mounted permanent magnets on the rotor where $d-q$ self-inductances are equal ( $L_{d}=L_{q}=L_{s}$ ). Therefore, the electrical torque will be completely proportional to the $q$-axis current according to (1).

\section{B. Modified qZS Model}

The proposed method requires a controllable inverter voltage $\left(v_{\mathrm{dc}}\right)$ that can be regulated to voltages both higher and lower than the input voltage $\left(V_{\text {in }}\right)$. Since the conventional qZS network is only capable of stepping up the input voltage, it has been modified by adding the shut-off network shown in Fig. 2 to allow for stepping down the voltage. As pictured, the shut-off circuit is comprised of an active switch $S_{1}$ and a diode $D_{1}$.

As illustrated in Fig. 3, the modified qZS circuit has three modes of operation: free mode, shoot-through mode, and shutoff mode. Switching between shoot-through mode and free mode steps up the input voltage while switching between the shut-off mode and the free mode steps down the input voltage. 


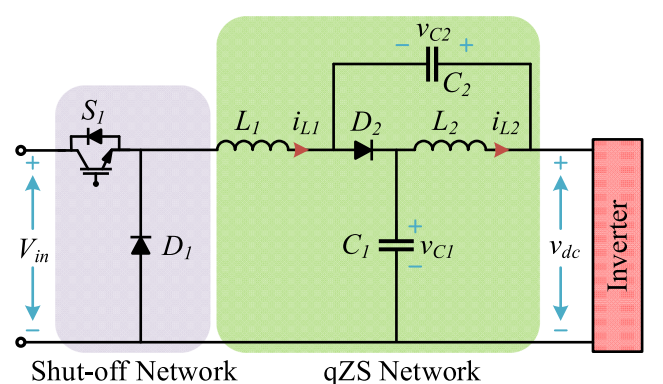

Fig. 2. Proposed modified qZS network.

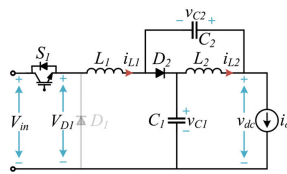

(a)

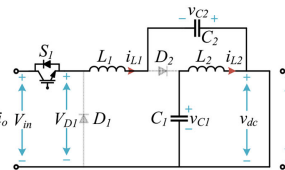

(b)

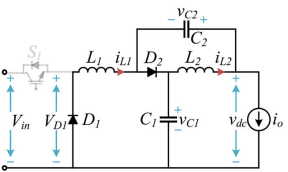

(c)
Fig. 3. Three modes of operation of the modified qZS network. (a) Free mode. (b) Shoot-through mode. (c) Shut-off mode.

The former operating condition is called step-up operation while the latter is called step-down operation, hereinafter.

The dynamic equations for modes (a) and (c) can be formulated as

$$
\begin{gathered}
L_{1} \frac{d i_{L 1}}{d t}=V_{D 1}-v_{C 1}, L_{2} \frac{d i_{L 2}}{d t}=-v_{C 2} \\
C_{1} \frac{d v_{C 1}}{d t}=i_{L 1}-i_{o}, C_{2} \frac{d v_{C 2}}{d t}=i_{L 2}-i_{o}
\end{gathered}
$$

whereas in free mode $V_{D 1}=V_{\text {in }}$ and in shut-off mode $V_{D 1}=0$. Similarly, the dynamic equations for the shoot-through mode (b) can be formulated as

$$
\begin{aligned}
L_{1} \frac{d i_{L 1}}{d t} & =V_{D 1}+v_{C 2}, L_{2} \frac{d i_{L 2}}{d t}=v_{C 1} \\
C_{1} \frac{d v_{C 1}}{d t} & =-i_{L 2}, C_{2} \frac{d v_{C 2}}{d t}=-i_{L 1}
\end{aligned}
$$

where $V_{D 1}$ is always equal to $V_{\text {in }}$ in this mode of operation.

\section{SVM Switching}

In this paper, SVM technique is used to realize the switching function. Using this technique, the reference voltages $v_{d}^{*}$ and $v_{q}^{*}$ (which will be determined from the proposed control method) can be directly realized by the inverter. The voltage space vector diagram for the inverter is shown in Fig. 4. Assuming that two adjacent active voltage vectors $V_{j}$ and $V_{k}$ in sector $S_{i}(i, j, k \in$ $\{1,2,3,4,5,6\}$ ) of the inverter and a zero voltage vector $V_{0}$ (or $V_{7}$ ) are chosen by SVM algorithm to be applied to the inverter, the duration of application of each voltage vector $\left(t_{j}, t_{k}\right.$, and $t_{0}$, respectively) can be found from [24]

$$
\left[\begin{array}{ccc}
\operatorname{Re}\left\{V_{j}\right\} & \operatorname{Re}\left\{V_{k}\right\} & \operatorname{Re}\left\{V_{0}\right\} \\
\operatorname{Im}\left\{V_{j}\right\} & \operatorname{Im}\left\{V_{k}\right\} & \operatorname{Im}\left\{V_{0}\right\} \\
1 & 1 & 1
\end{array}\right]\left[\begin{array}{c}
t_{j} \\
t_{k} \\
t_{0}
\end{array}\right]=\left[\begin{array}{c}
v_{d}^{*} \\
v_{q}^{*} \\
T_{s}
\end{array}\right]
$$

where $\operatorname{Re}\left\{V_{j}\right\}, \operatorname{Re}\left\{V_{k}\right\}, \operatorname{Re}\left\{V_{0}\right\}$ represent the projections of the vectors $V_{j}, V_{k}, V_{0}$ on the $d$-axis, and $\operatorname{Im}\left\{V_{j}\right\}$,

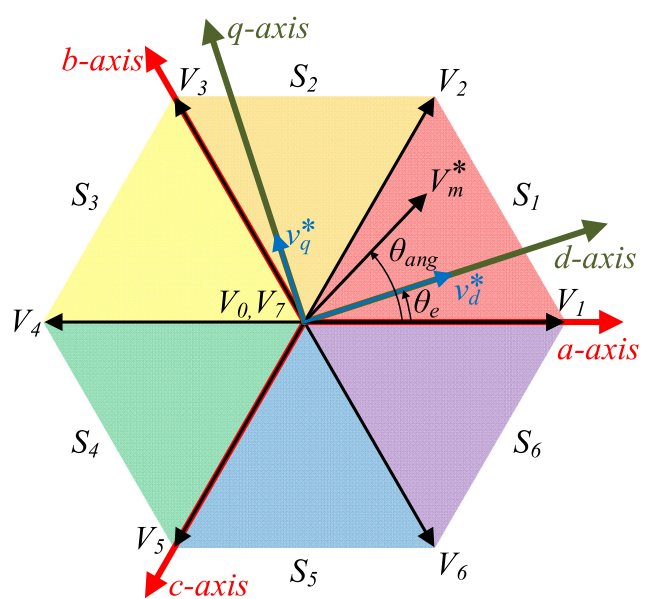

Fig. 4. Space vector diagram for the inverter of Fig. 1.

$\operatorname{Im}\left\{V_{k}\right\}, \operatorname{Im}\left\{V_{0}\right\}$ represent the projections of the vectors $V_{j}, V_{k}, V_{0}$ on the $q$-axis of a rotating $d-q$ reference frame synced with the rotor electrical angle $\left(\theta_{e}\right)$. Therefore

$$
\begin{aligned}
& \operatorname{Re}\left\{V_{j}\right\}=\frac{2}{3} v_{\mathrm{PN}} \cos \left(\theta_{e}-(i-1) \frac{\pi}{3}\right) \\
& \operatorname{Re}\left\{V_{k}\right\}=\frac{2}{3} v_{\mathrm{PN}} \cos \left(\theta_{e}-i \frac{\pi}{3}\right) \\
& \operatorname{Im}\left\{V_{j}\right\}=\frac{-2}{3} v_{\mathrm{PN}} \sin \left(\theta_{e}-(i-1) \frac{\pi}{3}\right) \\
& \operatorname{Im}\left\{V_{k}\right\}=\frac{-2}{3} v_{\mathrm{PN}} \sin \left(\theta_{e}-i \frac{\pi}{3}\right) .
\end{aligned}
$$

Solving (4) and (5), the duration of application of each voltage vector $\left(V_{j}, V_{k}\right.$, and $\left.V_{0}\right)$ can be calculated as

$$
\begin{aligned}
t_{j} & =\frac{\sqrt{3} T_{s} V_{m}^{*}}{v_{\mathrm{PN}}} \sin \left(i \frac{\pi}{3}-\theta_{\mathrm{ang}}\right) \\
t_{k} & =\frac{\sqrt{3} T_{s} V_{m}^{*}}{v_{\mathrm{PN}}} \sin \left(\theta_{\mathrm{ang}}-(i-1) \frac{\pi}{3}\right) \\
t_{0} & =T_{s}-t_{j}-t_{k} .
\end{aligned}
$$

In these equations

$$
V_{m}^{*}=\sqrt{v_{d}^{* 2}+v_{q}^{* 2}}, \theta_{\text {ang }}=\tan ^{-1}\left(\frac{v_{q}^{*}}{v_{d}^{*}}\right)+\theta_{e}
$$

where $\theta_{e}$ is the position of the PMSM rotor shaft with respect to the $a$-axis.

\section{Proposed Control System With Torque RipPle MiNIMIZATION CAPABILITY}

In this section, the proposed control system shown in Fig. 1 for the modified qZS network that can drive the PMSM with minimal torque ripple is described.

\section{A. Predictive Controller for PMSM}

The predictive PMSM controller is shown in Fig. 1. The predictive model of PMSM can be obtained by discretizing 
the equations in (1) using the trapezoidal integration method. Discretizing (1) yields the equations that incorporate the future values of $d$ - and $q$-axes currents over a one-step horizon

$$
\begin{aligned}
v_{d}(k)= & \frac{L_{d}}{T_{s}}\left(i_{d}(k+1)-i_{d}(k)\right)+\frac{R_{s}}{2}\left(i_{d}(k+1)\right. \\
& \left.+i_{d}(k)\right)-\frac{\omega_{e} L_{q}}{2}\left(i_{q}(k+1)+i_{q}(k)\right) \\
v_{q}(k)= & \frac{L_{q}}{T_{s}}\left(i_{q}(k+1)-i_{q}(k)\right)+\frac{R_{s}}{2}\left(i_{q}(k+1)\right. \\
& \left.+i_{q}(k)\right)+\frac{\omega_{e}}{2}\left(2 \psi_{m}+L_{d}\left(i_{d}(k+1)+i_{d}(k)\right)\right)
\end{aligned}
$$

where $T_{s}$ denotes the sampling time. According to (8), to drive $i_{d}(k+1)$ and $i_{q}(k+1)$ to a set of desired values $\left(i_{d}^{*}\right.$ and $i_{q}^{*}$ respectively), the $q$ - and $d$-axes voltages need to be set to the values found from left-hand side of $(8)$ when $i_{d}(k+1)$ and $i_{q}(k+1)$ are substituted with $i_{d}^{*}$ and $i_{q}^{*}$, respectively

$$
\begin{aligned}
v_{d}^{*}= & \frac{L_{d}}{T_{s}}\left(i_{d}^{*}-i_{d}(k)\right)+\frac{R_{s}}{2}\left(i_{d}^{*}+i_{d}(k)\right) \\
& -\frac{\omega_{e} L_{q}}{2}\left(i_{q}^{*}+i_{q}(k)\right) \\
v_{q}^{*}= & \frac{L_{q}}{T_{s}}\left(i_{q}^{*}-i_{q}(k)\right)+\frac{R_{s}}{2}\left(i_{q}^{*}+i_{q}(k)\right) \\
& +\frac{\omega_{e}}{2}\left(2 \psi_{m}+L_{d}\left(i_{d}^{*}+i_{d}(k)\right)\right) .
\end{aligned}
$$

Meaning that by applying $v_{d}^{*}$ and $v_{q}^{*}$ calculated from (9) to the PMSM using the inverter in each sampling time, the $d-q$-axes currents can be made to follow $i_{d}^{*}$ and $i_{q}^{*}$ references.

\section{B. Inverter Voltage Control Using Modified qZS Network}

According to Fig. 3, in nonshoot-through modes (a) and (c), the inverter's input voltage $\left(v_{\mathrm{dc}}\right)$ is equal to sum of the two capacitor voltages in the modified qZS network $\left(v_{\mathrm{PN}}=v_{C 1}+v_{C 2}\right)$. The amplitude of inverter output voltages seen by the PMSM that SVM can generate depends on the $v_{\mathrm{PN}}$ voltage. Consequently, the control objective for control of the modified qZS network will be to regulate $v_{\mathrm{PN}}$ to a desired value found from the torque ripple minimization technique discussed in the next section of the paper. The modified qZS controller block in Fig. 1, which is responsible for control of $v_{\mathrm{PN}}$, is shown in more detail in Fig. 5.

According to (2) and (3), $v_{\mathrm{PN}}$ can be controlled by controlling $i_{L 1}$. As pictured, the outer control loop uses a PI controller to provide the reference for $i_{L 1}$, which is denoted by $i_{L 1}^{*}$. The inner control loop then uses a predictive controller to accurately track $i_{L 1}^{*}$. It is worth mentioning that since in steady state $i_{L 1}=i_{L 2}$, there is no need to separately regulate $i_{L 2}$, meaning that controlling $i_{L 1}$ leads to control of $i_{L 2}$ automatically [25]. The proposed predictive current controller operates based on switching between shut-off mode and free mode during step-down operation and switching between shoot-through mode and free mode during step-up operation. The output of the predictive controller provides duty cycles for shut-off mode

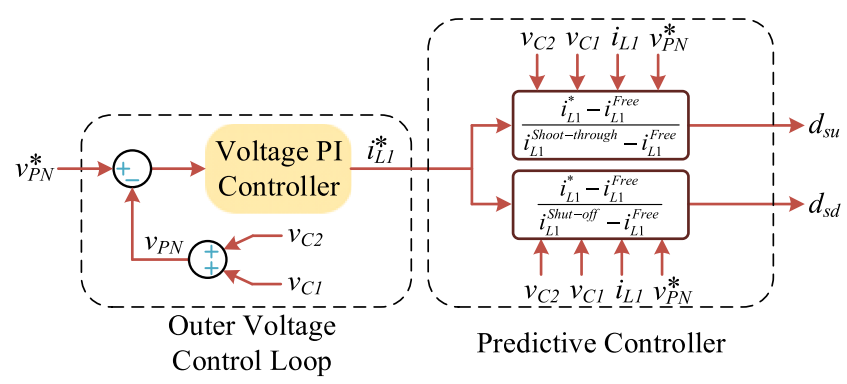

Fig. 5. Proposed inverter voltage controller for modified qZS network.

during step-down operation $\left(d_{\mathrm{sd}}\right)$, and shoot-through mode during step-up operation $\left(d_{\mathrm{su}}\right)$. The $d_{\mathrm{sd}}$ is the ratio of the duration of the shut-off mode to the sampling time during step-down operation, while $d_{\mathrm{su}}$ is the ratio of duration of the shoot-through mode to the sampling time during step-up operation. The predictive controller generates $d_{\mathrm{su}}=0$ during step-down operation and uses $d_{\mathrm{sd}}$ to regulate $i_{L 1}$, while during the step-up operation, it generates $d_{\mathrm{sd}}=0$ and uses $d_{\mathrm{su}}$ to regulate $i_{L 1}$. As a result, the controller needs to determine whether step-down or step-up operation should be triggered and subsequently calculate the required duty cycles. The predictive controller decides to trigger step-up operation if $v_{\mathrm{PN}}^{*}>V_{\mathrm{in}}$ and likewise decides to trigger step-down operation if $v_{\mathrm{PN}}^{*} \leq V_{\mathrm{in}}$. To calculate each duty cycle, the discretized voltage equation for $\mathrm{L} 1$ is needed

$$
L_{1} \frac{d i_{L 1}(t)}{d t}=v_{L 1}(t) .
$$

In this equation, $v_{L 1}(t)$ represents the instantaneous value of the inductor $L_{1}$ voltage. Using the Euler forward discretization method and assuming that the modified qZS network operates in only one mode during the sampling time meaning that $v_{L 1}(t)$ is constant and equal to $V_{L 1}$ during the sampling time, the value of $i_{L 1}$ at the end of the sampling time can be found from

$$
i_{L 1}(k+1)=\frac{T_{s} V_{L 1}}{L_{1}}+i_{L 1}(k)
$$

where $V_{L 1}$ for modes (a)-(c) is equal to

$$
V_{L 1}= \begin{cases}V_{\text {in }}-v_{C 1} & \text { Free Mode } \\ V_{\text {in }}+v_{C 2} & \text { Shoot }- \text { through Mode } \\ -v_{C 1} & \text { Shut }- \text { off Mode. }\end{cases}
$$

On the other hand, if each of these voltages are applied to the inductor $L_{1}$ for an entire sampling time, the resulting $i_{L 1}(k+1)$ at the end of the sampling time is denoted by

$$
i_{L 1}(k+1)=\left\{\begin{array}{lc}
i_{L 1}^{\text {Free }} & \text { Free Mode } \\
i_{L 1}^{\text {Shoot-through }} & \text { Shoot }- \text { through Mode } \\
i_{L 1}^{\text {Shut-off }} & \text { Shut }- \text { off Mode }
\end{array}\right.
$$

hereinafter. Using this terminology, for the step-down operation, the proposed predictive controller calculates the amount of time that the shut-off mode needs to be applied to the converter to regulate $i_{L 1}$ to its reference value based on the method proposed 
in [21] and [26]

$$
d_{\mathrm{sd}}=\frac{i_{L 1}^{*}-i_{L 1}^{\text {Free }}}{i_{L 1}^{\text {Shut }- \text { off }}-i_{L 1}^{\text {Free }}}
$$

where $t_{\mathrm{sd}}=d_{\mathrm{sd}} T_{s}$ is the amount of time that the shut-off mode needs to be applied to qZS during each sampling time. In other words, $d_{\mathrm{sd}}$ in (14) is the duty cycle of $S_{1}$ in Fig. 1 . For the rest of the sampling time, the modified qZS network remains in free mode. Similarly, for the step-up operation, the proposed predictive controller calculates the amount of time that the shootthrough mode needs to be applied to the converter as [21], [26]

$$
d_{\mathrm{su}}=\frac{i_{L 1}^{*}-i_{L 1}^{\text {Free }}}{i_{L 1}^{\text {Shoot-through }}-i_{L 1}^{\text {Free }}}
$$

where $t_{\mathrm{su}}=d_{\mathrm{su}} T_{s}$ represents the amount of time that shootthrough mode must be applied to qZS by SVM method during each sampling time. For the rest of the sampling time, the modified qZS network remains in free mode.

\section{Torque Ripple Minimization}

The flexibilities provided by the proposed modified qZS network can be leveraged to minimize the delivered torque ripples through two cascaded mechanisms described in this section. The two proposed torque ripple minimization techniques are denoted by the voltage-based torque ripple minimization and switchingsequence based torque ripple minimization hereinafter.

1) Voltage-Based Torque Ripple Minimization: As it will be discussed below, the amount of delivered torque ripple generated by the PMSM of Fig. 1 is dependent on the input voltage of the inverter. Further, it will be shown in this section that there is an optimum voltage profile for the input voltage of the inverter that leads to least amount of torque ripple. Unlike the traditional motor drive systems with fixed voltage source inverters, the modified qZS network provides great flexibility to regulate the input voltage of the inverter to any desired value. The optimum voltage profile for the inverter input voltage $v_{\mathrm{PN}}^{*}$ (denoted as $v_{\mathrm{PN} \text { _opt }}^{*}$ hereinafter), will be obtained in this section subject to minimization of the produced electrical torque ripple.

To find $\mathrm{v}_{\mathrm{PN} \text { _opt }}^{*}$ in this section, it is assumed that $i_{d}(k)=i_{d}^{*}$ and $i_{q}(k)=i_{q}^{*}$ at the start of each sampling time since the discussed predictive PMSM controller converges the $d q$-axis currents to their references in a short amount of time. Furthermore, since the real values of $i_{q}(k)$ and $i_{d}(k)$, which are acquired through measurements (from current sensors) can be distorted due to noise, they might induce unwanted noise to the obtained voltage $v_{\mathrm{PN} \text { _opt }}^{*}$ in (24) in the paper. Besides that, during transients, this assumption leads to a faster response for the system, which means that it prepares the Z-source output voltage to accommodate the new operating point for the PMSM. Therefore, solving the $q$-axis differential equation in (1) using the Euler forward method for the duration of the sampling time yields

$$
i_{q}(t)-i_{q}^{*}=\frac{1}{L_{q}}\left(v_{q}-R_{s} i_{q}^{*}-\omega_{e}\left(L_{d} i_{d}^{*}+\psi_{m}\right)\right) t .
$$

Since the absolute value of change in $q$-axis current is a determinative factor for torque ripple, to assess the torque ripple, positive function $\Delta i_{q}(t)$ is defined as

$$
\Delta i_{q}(t) \doteq\left(\frac{1}{L_{q}}\left(v_{q}-R_{s} i_{q}^{*}-\omega_{e}\left(L_{d} i_{d}^{*}+\psi_{m}\right)\right)\right)^{2} t
$$

Applying two adjacent active voltage vectors $V_{j}$ and $V_{k}$ in sector $S_{i}$ to the motor results in $q$-axis voltages $\operatorname{Im}\left\{V_{j}\right\}$ and $\operatorname{Im}\left\{V_{k}\right\}$, respectively, [described in (5)]. Therefore, substituting $\operatorname{Im}\left\{V_{j}\right\}$ and $\operatorname{Im}\left\{V_{k}\right\}$ into (17), the voltage-based torque ripple equation can be defined as

$$
\begin{aligned}
T_{\mathrm{VTR}} \doteq & \frac{3 p \psi_{m}}{2 T_{s}} \int_{0}^{T_{s}} \Delta i_{q}(t) d t=\frac{3 p \psi_{m}}{2 T_{s}}\left(\int_{0}^{t_{j}} \Delta i_{q j}(t) d t\right. \\
& \left.+\int_{0}^{t_{k}} \Delta i_{q k}(t) d t+\int_{0}^{t_{0}} \Delta i_{q 0}(t) d t\right)
\end{aligned}
$$

where $\Delta i_{q j}(t), \Delta i_{q k}(t)$, and $\Delta i_{q 0}(t)$ are obtained from (17) and are the changes made to the $q$-axis current over the time frames in which the inverter voltage vectors $V_{j}, V_{k}$, and $V_{0}$ (or $V_{7}$ ) are applied to the motor, respectively. Substituting (17) into (18) and integration results in

$$
\begin{aligned}
T_{\mathrm{VTR}}= & \frac{3 p \psi_{m}}{2 T_{s}}\left(\left(\frac{1}{L_{q}}\left(\operatorname{Im}\left\{V_{j}\right\}-R_{s} i_{q}^{*}-\omega_{e}\left(L_{d} i_{d}^{*} \psi_{m}\right)\right)\right)^{2}\right. \\
& \times \frac{t_{j}^{2}}{2}+\left(\frac{1}{L_{q}}\left(\operatorname{Im}\left\{V_{k}\right\}-R_{s} i_{q}^{*}-\omega_{e}\left(L_{d} i_{d}^{*} \psi_{m}\right)\right)\right)^{2} \\
& \left.\times \frac{t_{k}{ }^{2}}{2}+\left(\frac{1}{L_{q}}\left(-R_{s} i_{q}^{*}-\omega_{e}\left(L_{d} i_{d}^{*}+\psi_{m}\right)\right)\right)^{2} \frac{t_{0}{ }^{2}}{2}\right) .
\end{aligned}
$$

Further substituting (5) and (6) into (19) results in

$$
\begin{aligned}
T_{\mathrm{VTR}}= & K\left(\left(k_{4} v_{\mathrm{PN} \_ \text {opt }}^{*}+k_{1}\right)^{2}\left(\frac{1}{v_{\mathrm{PN} \text { _opt }}^{*}} k_{2}\right)^{2}\right. \\
& +\left(k_{5} v_{\mathrm{PN} \_ \text {opt }}^{*}+k_{1}\right)^{2}\left(\frac{1}{v_{\mathrm{PN} \text { _opt }}^{*}} k_{3}\right)^{2}+\left(k_{1}\right)^{2}\left(T_{s}\right. \\
& \left.\left.-\frac{1}{v_{\mathrm{PN} \_ \text {opt }}^{*}}\left(k_{2}+k_{3}\right)\right)^{2}\right)
\end{aligned}
$$

where

$$
\begin{aligned}
K & =\frac{3 p \psi_{m}}{4 T_{s} L_{q}{ }^{2}}, k_{1}=-R_{s} i_{q}^{*}-\omega_{e}\left(L_{d} i_{d}^{*}+\psi_{m}\right) \\
k_{2} & =\sqrt{3} T_{s} V_{m}^{*} \sin \left(i \frac{\pi}{3}-\theta_{\mathrm{ang}}\right) \\
k_{3} & =\sqrt{3} T_{s} V_{m}^{*} \sin \left(\theta_{\mathrm{ang}}-(i-1) \frac{\pi}{3}\right) \\
k_{4} & =\frac{-2}{3} \sin \left(\theta_{e}-(i-1) \frac{\pi}{3}\right) \\
k_{5} & =\frac{-2}{3} \sin \left(\theta_{e}-i \frac{\pi}{3}\right) .
\end{aligned}
$$




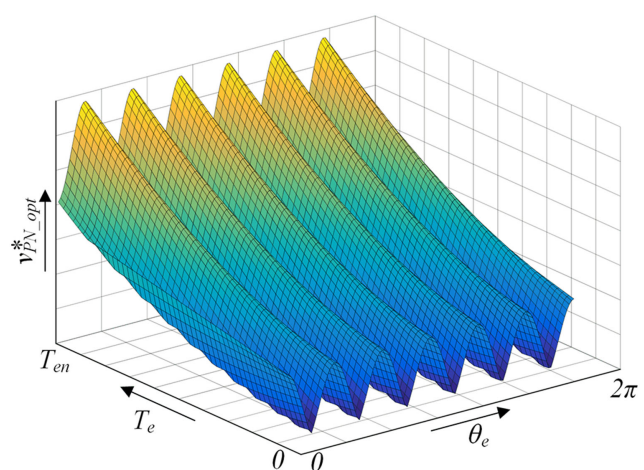

Fig. 6. Surface diagram of the optimized voltage profile as a function of delivered torque at nominal PMSM shaft speed.

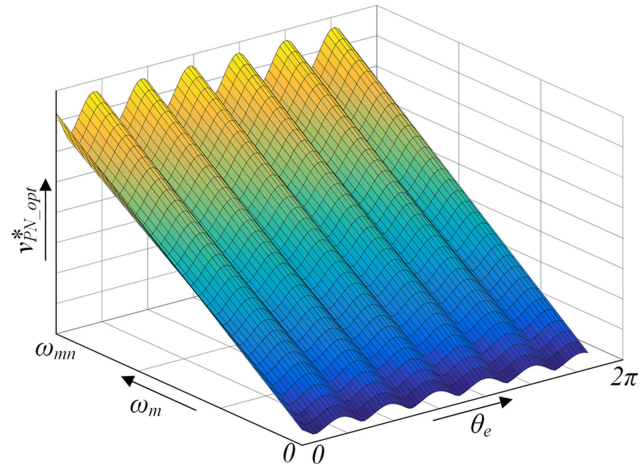

Fig. 7. Surface diagram of the optimized voltage profile as a function of speed when delivering nominal torque.

To minimize the torque ripple, the $T_{\mathrm{VTR}}$ derivative with respect to the inverter voltage should be set to zero

$$
\frac{d T_{\mathrm{VTR}}}{d v_{\mathrm{PN} \_ \text {opt }}^{*}}=0 .
$$

Solving this equation results in a voltage profile that the modified qZS network should produce to minimize the torque ripple

$$
v_{\mathrm{PN} \_ \text {opt }}^{*}=-\frac{\left(k_{1} k_{2}\right)^{2}+\left(k_{1} k_{3}\right)^{2}+k_{1}^{2}\left(k_{2}+k_{3}\right)^{2}}{k_{1} k_{2}{ }^{2} k_{4}+k_{1} k_{3}{ }^{2} k_{5}-T_{s} k_{1}^{2}\left(k_{2}+k_{3}\right)} .
$$

Fig. 6 illustrates the resulting optimized voltage profile $v_{\mathrm{PN} \_ \text {opt }}^{*}$ as a function of electrical rotor position and delivered torque from zero to its nominal value $T_{e n}$, while the shaft speed is at the nominal value $\omega_{m n}$. Similarly, Fig. 7 illustrates the resulting optimized voltage profile as a function of electrical rotor position and shaft speed from zero to its nominal value $\omega_{m n}$ when delivering nominal torque $T_{e n}$.

As pictured, when the motor is operating at a specific operating point, delivering certain amount of torque at a particular shaft speed, the value of $v_{\mathrm{P} \text { _opt }}^{*}$ oscillates with a frequency of $6 \omega_{e}$. By accurately regulating $v_{\mathrm{PN}}$ to track the obtained $v_{\mathrm{PN} \_o p t}^{*}$ profile, the torque ripple will be minimized. However, at high speed operation of PMSM, the bandwidth of oscillations of $v_{\mathrm{PN} \text { _opt }}^{*}$ might exceed the bandwidth of the dynamic response of the Z-source network, making it difficult for the Z-source network to follow the desired voltage profile. This condition does not occur because the controller is unable to follow the voltage profile, but it happens in applications where the qZS converter design criteria lead to a design with a slow dynamic response (low bandwidth). For these particular situations, a suboptimal constant voltage profile solution can be identified, which still significantly minimizes the torque ripple. Choosing a constant value for $v_{\mathrm{PN}}$ more than the peak value of $v_{\mathrm{PN} \text { _opt }}^{*}$ increases the torque ripple according to the torque ripple equation in (20) and thus it is not appropriated. Also, choosing a value less than the peak value of $v_{\mathrm{PN} \text { _opt }}^{*}$ prohibits the PMSM to provide the required torque to the load throughout each period. Meaning that, according to (16), if the input voltage of the inverter is less than the voltage profile in (23), then the inverter cannot provide enough voltage for PMSM to drive $i_{q}$ to its reference value, resulting in failure to produce the required load torque. Therefore, the peak value of the $v_{\mathrm{PN} \text { _opt }}^{*}$ can be chosen as the suboptimal solution to the problem of torque ripple minimization.

Finally, it is worth mentioning that the step-up operation of the modified qZS network imposes a limitation to increasing of $v_{\mathrm{PN}}^{*}$ since generating a higher value for this voltage requires a larger time duration spent in the shoot-through mode according to the voltage gain equation of qZS network [27]. The SVM block in Fig. 1 outputs time durations for realizing each inverter voltage vector. Among them, $t_{0}$ is the time duration that the inverter must produce zero voltage vector. On the other hand, $d_{\mathrm{su}}$ obtained from (15) has to be applied to the inverter when the inverter realizes the zero voltage vector since the shootthrough mode also provides a form of zero voltage vector to inverter. Therefore, the inverter needs to realize the zero voltage vector for a duration of at least $t_{\mathrm{su}}=d_{\mathrm{su}} T_{s}$, which means that $t_{0} \geq t_{\mathrm{su}}$. Considering that $t_{0}+t_{j}+t_{k}=T_{s}$, the inequality can be calculated as

$$
\left(T_{s}-t_{j}-t_{k}\right) \geq t_{\mathrm{su}} .
$$

Substituting (6) into (24) leads to

$$
\begin{aligned}
& \left(T_{s}-\frac{\sqrt{3} T_{s} V_{m}^{*}}{v_{\mathrm{PN}_{-} \mathrm{lim}}^{*}} \sin \left(i \frac{\pi}{3}-\theta_{\mathrm{ang}}\right)-\frac{\sqrt{3} T_{s} V_{m}^{*}}{v_{\mathrm{PN}_{-} \text {lim }}^{*}} \sin \left(\theta_{\mathrm{ang}}\right.\right. \\
& \left.\left.-(i-1) \frac{\pi}{3}\right)\right) \geq t_{\mathrm{su}}
\end{aligned}
$$

and simplifying this equation produces an inequality that describes the limit on $v_{P N}^{*}$

$$
\begin{aligned}
v_{\mathrm{PN} \_l i m}^{*} \geq & \left(\frac{\sqrt{3} V_{m}^{*}}{1-d_{s u}} \sin \left(i \frac{\pi}{3}-\theta_{\mathrm{ang}}\right)+\frac{\sqrt{3} V_{m}^{*}}{1-d_{s u}} \sin \left(\theta_{\mathrm{ang}}\right.\right. \\
& \left.\left.-(i-1) \frac{\pi}{3}\right)\right) .
\end{aligned}
$$

Therefore, this limitation should be checked continuously to assure the proper operation of the system.

2) Switching-Based Torque Ripple Minimization: In addition to finding the $v_{\mathrm{PN} \_ \text {opt }}^{*}$ that reduces the torque ripple, the torque ripple can be further reduced by modifying the conventional SVM algorithm to leverage the flexibility provided by inclusion of shoot-through modes for devising a switching sequence that further reduces the $q$-axis current ripples (and 


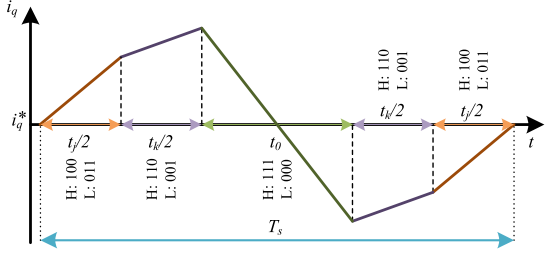

(a)

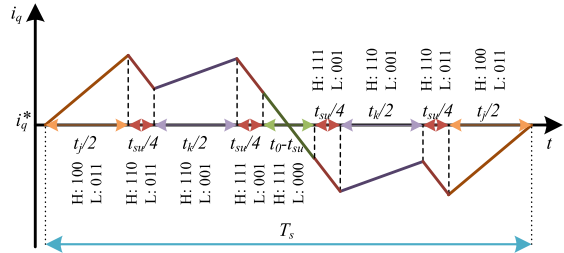

(b)

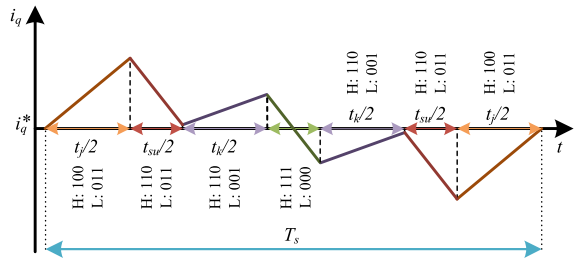

(c)

Fig. 8. $q$-axis current trajectories for (a) SVM switching without Z-source network, (b) conventional SVM switching technique with Z-source network, and (c) proposed SVM switching technique with Z-source network.

hence the torque ripple). To demonstrate the effect of switching sequence on the torque ripple, a case study is provided here. In this case study, the SVM is operating in sector $S_{1}$ where active voltage vectors $V_{1}$ and $V_{2}$ as well as the zero voltage vector $V_{7}$ are chosen to be realized by the inverter using the alternating zero voltage vector method described in [28]. Using this method while operating in $S_{1}$, at the start of the sampling time, the status of conduction of the upper switches of a conventional inverter are $S_{a H}=\mathrm{ON}, S_{b H}=\mathrm{OFF}$, and $S_{c H}=\mathrm{OFF}$ (shown by $H=100$ hereinafter, where $H$ represents the conduction status of the upper switches), while the conduction status for the lower switches are $S_{a L}=\mathrm{OFF}, S_{b L}=\mathrm{ON}$, and $S_{c L}=\mathrm{ON}$ (shown by $\mathrm{L}=011$ hereinafter for lower switches) for $t_{j} / 2 \mathrm{~s}$ to realize the active voltage vector $V_{1}$. Then, the inverter generates the active voltage vector $V_{2}$ using $H=110$ and $L=001$ for $t_{k} / 2 \mathrm{~s}$. Next, the inverter generates zero voltage vector $V_{7}$ using $\mathrm{H}=111$ and $\mathrm{L}=000$ for $t_{0} \mathrm{~s}$. Once more, the inverter generates active voltage vector $V_{2}$ using $H=110$ and $L=001$ for $t_{k} / 2 \mathrm{~s}$, and finally generates active voltage vector $V_{1}$ again using $H=100$ and $L=011$ for $t_{j} / 2 \mathrm{~s}$. The effect of this switching sequence on the $q$-axis current trajectory is illustrated in Fig. 8(a).

On the other hand, in a Z-source inverter, the shoot-through modes need to be included in the switching sequence as well. Fig. 8(b) illustrates the conventional switching sequence for a Z-source inverter [27] where the inverter is responsible to realize the shoot-through mode for the modified qZS network for $t_{\mathrm{su}}=d_{\mathrm{su}} T_{s}$. As pictured, the shoot-through modes are triggered starting at time instances when the inverter voltage vector is being transitioned from one vector to another one. For example, according to Fig. 8(b) after the inverter has spent $t_{j} / 2 \mathrm{~s}$ on $V_{1}$ using $H=100$ and $L=011$, a shoot-through state is realized using $H=110$ and $L=011$, followed by generating $V_{2}$ using $H=110$ and $L=001$. Since in this switching method, the switching vectors change four times during a switching period, the duration of a shoot-though state after each change needs to be $t_{\mathrm{su}} / 4$.

To further decrease the $i_{q}$ ripple (and consequently torque ripple), the switching method illustrated in Fig. 8(c) is proposed. In this method, instead of realizing the shoot-through mode starting at every transition, the shoot-through is realized only when a transition between two active voltage vectors is happening. For example, for the previous studied case of operating in $S_{1}$, using the proposed technique the shoot-through occurs only when the inverter intends to realize active voltage vector $V_{2}$ after it has spent $t_{j} / 2 \mathrm{~s}$ on active voltage vector $V_{1}$ and vice versa. Thus, the

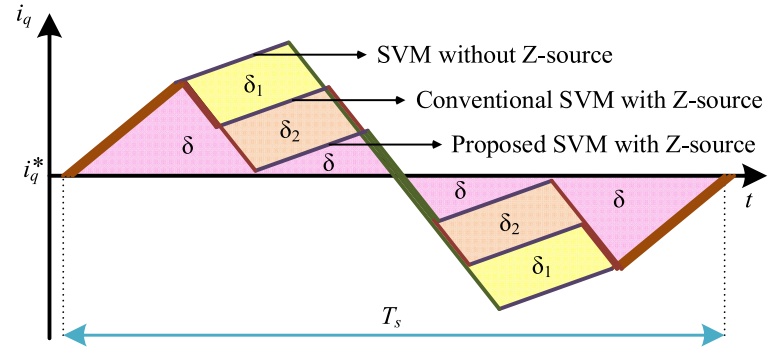

Fig. 9. Comparison between $q$-axis current trajectories for the three switching techniques in Fig. 8.

duration of shoot-through between only active voltage vectors needs to be $t_{\mathrm{su}} / 2$.

To investigate the merits of the proposed switching method, the switching-based torque ripple is defined as

$$
T_{\mathrm{STR}} \doteq \frac{1}{T_{s}} \int_{0}^{T_{s}}\left|T_{e}(t)-T_{e}^{*}\right| d t
$$

that can be formulated based on $i_{q}$ as

$$
T_{\mathrm{STR}}=\frac{3 p \psi_{m}}{2 T_{s}} \int_{0}^{T_{s}}\left|i_{q}(t)-i_{q}^{*}\right| d t .
$$

To evaluate (28) for the three switching strategies in Fig. 8, the three $q$-axis current trajectories in this figure are overlaid and illustrated in Fig. 9. As pictured, the absolute value of the area under the $q$-axis error current trajectory $\left|i_{q}(t)-i_{q}^{*}\right|$ for SVM without Z-source network [see Fig. 8(a)] is equal to $2\left(\delta+\delta_{1}+\delta_{2}\right)$. This value for conventional SVM for Z-source network [see Fig. 8(b)] and the proposed SVM with Z-source network [see Fig. 8(c)] are $2\left(\delta+\delta_{2}\right)$ and $2 \delta$, respectively. According to (28), less area under the $q$-axis error current trajectory leads to less switching-related torque ripple. Therefore, according to (28) and Fig. 9, the switching-based torque ripple generated by the proposed method is $2 \delta_{2}$ less than the switchingbased torque ripple generated by the conventional SVM for an inverter with a Z-source network.

\section{EXPERIMENTAL RESULTS}

The control system has been implemented using a digital signal processor from Texas Instruments (TMS320F28335). For the speed control loop, $K_{P}$ and $K_{I}$ of the PI controller have been set to 0.063 and 12.57, respectively. For voltage control loop of qZS, these values have been set to $K_{P}=0.72$ and $K_{I}=46.3$. The PI controllers are optimized to have the minimum overshoot 
TABLE I

MOTOR PARAMETERS

\begin{tabular}{lll}
\hline \hline Parameter & Symbol & Value \\
\hline Number of pole pairs & $p$ & 4 \\
Rated torque $(N . m)$ & $T_{r}$ & 4.2 \\
Rated speed $(\mathrm{rpm})$ & $\omega_{\text {rated }}$ & 2500 \\
Rated power $(W)$ & $P_{r}$ & 1000 \\
DC link nominal voltage $(\mathrm{V})$ & $V_{n}$ & 400 \\
Stator inductance $(\mathrm{mH})$ & $L_{s}$ & 3.15 \\
Stator resistance $(\Omega)$ & $r_{s}$ & 0.9 \\
Mechanical inertia $\left(\mathrm{kg} . \mathrm{cm}^{2}\right)$ & $J$ & 1.1 \\
Torque constant $(\mathrm{N} . \mathrm{m} / \mathrm{A})$ & $K_{T}$ & 0.62 \\
\hline
\end{tabular}

and settling time. For generating all of the results, the PI coefficients have been kept constant. The qZS parameters are as follows: $L_{1}=L_{2}=1500 \mu \mathrm{H}$ and $C_{1}=C_{2}=400 \mu \mathrm{F}$. The sampling time of the proposed method is considered to be $T_{s}=$ $100 \mu$ s. Parameters of the motor under study are given in Table I.

Furthermore, it is worth mentioning that in all the experiments provided in this section, the discussed predictive motor controller has been used to control the PMSM and the calculation delay time has been compensated for all the experiments according to the technique explained in [29]. Hence, at the start of the sampling time $k$ all the measurement will be performed and the switching scheme obtained from the previous interval will be applied to the converter using SVM over the current sampling interval. Then, an estimation of the $d q$-axis current values at time $k+1$ considering that the current switching pattern will produce $v_{d}^{*}(k)$ and $v_{q}^{*}(k)$ will be calculated using (8). Then, the estimated currents $i_{d}(k+1)$ and $i_{q}(k+1)$ will be used in (9) to calculate the voltage references $v_{d}^{*}(k+1)$ and $v_{q}^{*}(k+1)$. These voltage references will be used to calculate the voltage vector application times using SVM and the new switching pattern will be applied to the inverter at the start of the next sampling time $\mathrm{k}+1$. Furthermore, these voltages will be used to calculate $V_{m}^{*}$ and finally $v_{\mathrm{PN} \text { _opt }}^{*}$. The same procedure will is utilized to calculate the value of $d_{\mathrm{sd}}$ or $d_{\mathrm{su}}$ for the start of the next sampling interval. It is also worth mentioning that the PMSM produced torque waveforms in this section have been calculated according to (1) since the torque is proportional to $i_{q}$. Furthermore, the $d$ - and $q$-axes currents have been acquired by performing park transformation on three-phase currents.

In the first experiment, the steady-state operation of the motor is evaluated when the inverter is being fed by a $400 \mathrm{~V}$ constant dc source (modified qZS network is bypassed and the inverter's input is connected directly to a dc source). In this experiment, the motor is operating at $500 \mathrm{r} / \mathrm{min}$, while the shaft is delivering $4 \mathrm{~N} \cdot \mathrm{m}$ of torque. The waveforms in Fig. 10(a)-(d) show the measurement results for PMSM three-phase currents, delivered torque, $d$-axis motor current, and shaft speed, respectively. The THD of the PMSM currents in this experiment is equal to $6.84 \%$ and the peak to peak torque ripple is equal to $1.831 \mathrm{~N} \cdot \mathrm{m}$. The THD of the PMSM phase currents has been calculated by MATLAB using the imported data acquired from the oscilloscope.

The same experiment has been performed while the inverter is fed by the modified qZS network controlled using the proposed control system. In this condition, the torque minimization

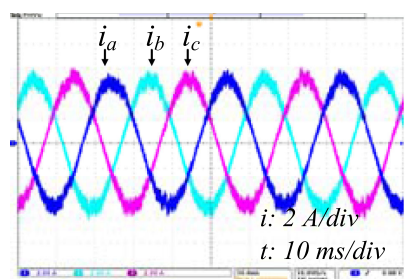

(a)

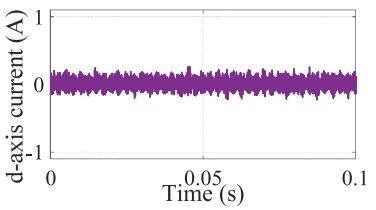

(c)

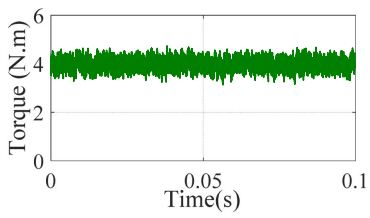

(b)

(d)

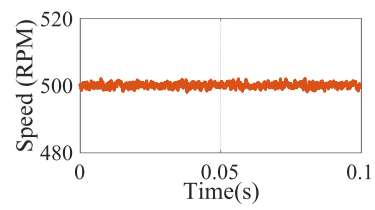

Fig. 10. Steady state PMSM operation with $400 \mathrm{~V}$ dc input voltage at $500 \mathrm{r} / \mathrm{min}$ speed. (a) PMSM three-phase currents. (b) Delivered torque. (c) $d$-axis motor current. (d) Shaft speed.

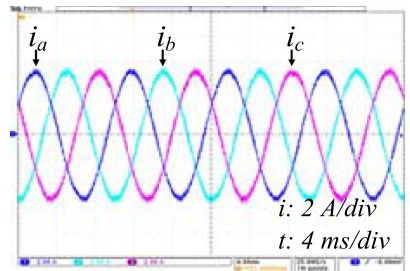

(a)

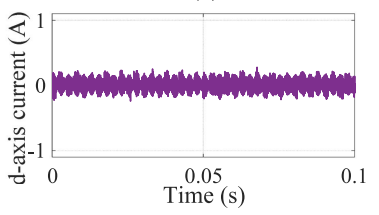

(c)

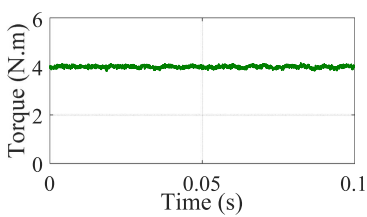

(b)

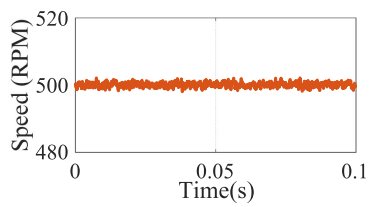

(d)
Fig. 11. Steady-state PMSM operation with the modified qZS network at $500 \mathrm{r} / \mathrm{min}$ speed. (a) PMSM three-phase currents. (b) Delivered torque. (c) $d$-axis motor current. (d) Shaft speed.

formula in (23) provides a voltage profile reference for the qZS. The waveforms in Fig. 11(a)-(d) show the measurement results for PMSM three-phase currents, delivered torque, $d$-axis current, and shaft speed, respectively. The THD of the PMSM phase currents using the proposed method is equal to $1.93 \%$ in this condition. This shows a $4.91 \%$ reduction compared to the case with a constant dc source. The peak to peak delivered torque ripple in this condition is equal to $0.438 \mathrm{~N} \cdot \mathrm{m}$. This shows a $1.393 \mathrm{~N} \cdot \mathrm{m}$ reduction ( $76.08 \%$ reduction) compared to the case with a constant dc source. Results of this experiment show that compared with feeding the inverter with a constant dc source, the proposed method provides a more satisfactory steady-state response with less current THD and torque ripple.

Fig. 12 illustrates the waveforms for modified qZS network quantities for the previous experiment. This figure illustrates that the proposed MMPC controller for qZS effectively stabilizes the qZS control variables.

In the next experiment, the steady-state operation of the motor is evaluated when the inverter is being fed by a $400 \mathrm{~V}$ constant dc source and motor is operating at $2500 \mathrm{r} / \mathrm{min}$ while delivering $4 \mathrm{~N} \cdot \mathrm{m}$ torque. The waveforms in Fig. 13(a)-(d) show 


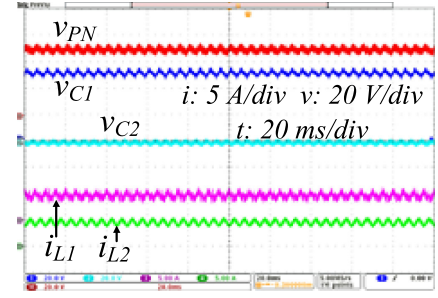

Fig. 12. Waveforms for qZS variables for the experiment of Fig. 11.

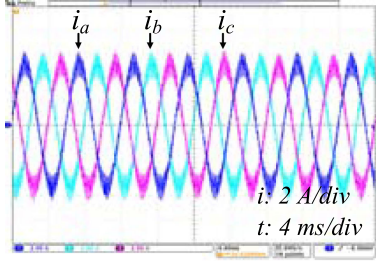

(a)

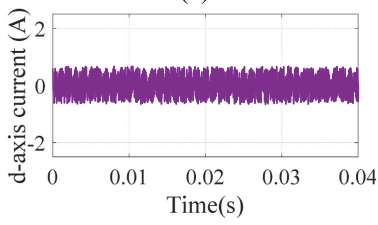

(c)

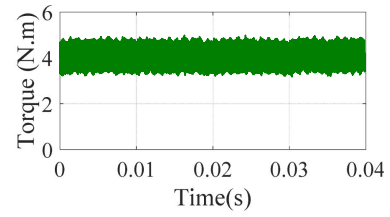

(b)

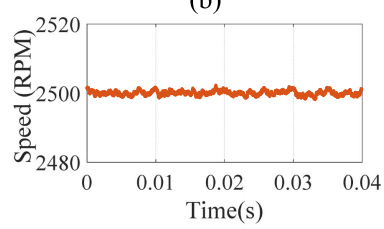

(d)
Fig. 13. Steady-state PMSM operation with $400 \mathrm{~V}$ dc input voltage at $2500 \mathrm{r} / \mathrm{min}$ speed. (a) PMSM three-phase currents. (b) Delivered torque. (c) $d$-axis motor current. (d) Shaft speed.

the measurement results for PMSM three-phase currents, delivered torque, $d$-axis motor current, and shaft speed, respectively. The THD of the PMSM currents in this experiment is equal to $11.32 \%$ and the peak to peak torque ripple is equal to $1.757 \mathrm{~N} \cdot \mathrm{m}$. The THD of the PMSM phase currents has been calculated by MATLAB using the imported data acquired from the oscilloscope.

The same experiment has been performed while the inverter is fed by the modified qZS network controlled using the proposed control system. In this speed, since the frequency of oscillation of the voltage profile generated by (23) exceeds beyond the qZS bandwidth, the suboptimal solution has been applied as a reference for the qZS. The waveforms in Fig. 14(a)-(d) show the measurement results for PMSM three-phase currents, delivered torque, $d$-axis current, and shaft speed, respectively. The THD of the PMSM phase currents using the proposed method is equal to $7.04 \%$ in this condition. This shows a $4.28 \%$ reduction compared to the case with a constant dc source. The peak to peak delivered torque ripple in this condition is equal to $1.147 \mathrm{~N} \cdot \mathrm{m}$. This shows a $0.610 \mathrm{~N} \cdot \mathrm{m}$ reduction $(34.72 \%$ reduction) compared to the case with a constant dc source. Results of this experiment show that compared with feeding the inverter with a constant dc source, although the suboptimal solution has been used, the proposed method provides a more satisfactory steady-state response with less current THD and torque ripple.

Fig. 15 illustrates the waveforms for modified qZS network quantities for the previous experiment. This figure illustrates that the proposed MMPC controller for qZS effectively stabilizes the qZS control variables.

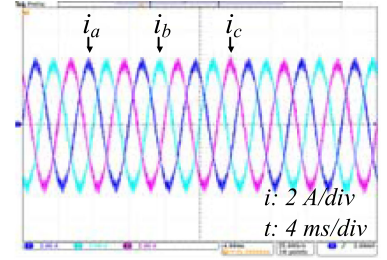

(a)

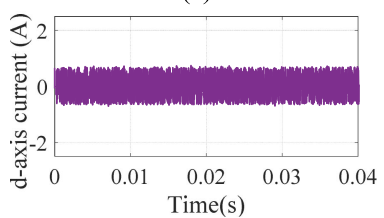

(c)

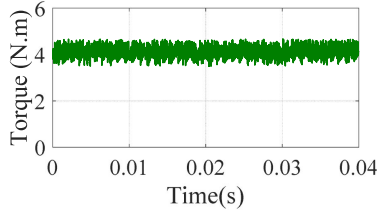

(b)

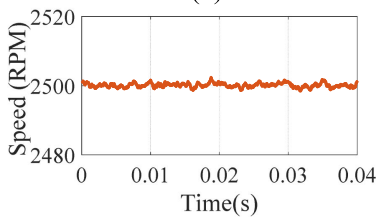

(d)
Fig. 14. Steady-state PMSM operation with the modified qZS network at $2500 \mathrm{r} / \mathrm{min}$ speed. (a) PMSM three-phase currents. (b) Delivered torque. (c) $d$-axis motor current. (d) Shaft speed.

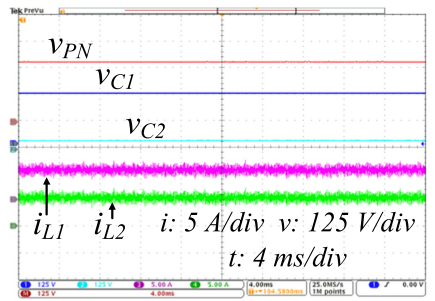

Fig. 15. Waveforms for qZS variables for the experiment of Fig. 14.

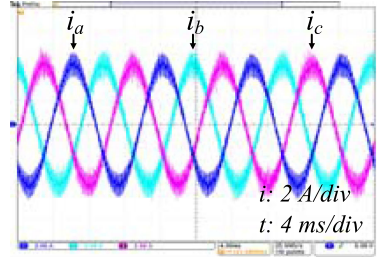

(a)

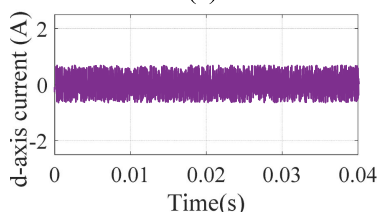

(c)

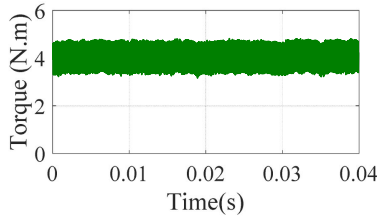

(b)

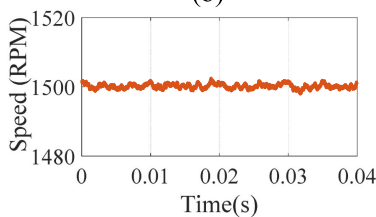

(d)
Fig. 16. Steady-state operation with $400 \mathrm{~V}$ dc input voltage at $1500 \mathrm{r} / \mathrm{min}$ speed. (a) PMSM three-phase currents. (b) Delivered torque. (c) $d$-axis motor current. (d) Shaft speed.

The next two experiments, reiterate the two previous experiments except that the motor speed is set to $1500 \mathrm{r} / \mathrm{min}$ to evaluate the performance of the proposed method in various shaft speed conditions. The delivered torque in this condition is equal to $4 \mathrm{~N} \cdot \mathrm{m}$. The waveforms in Fig. 16(a)-(d) show the measurement results for PMSM three-phase currents, delivered torque, $d$-axis current, and shaft speed, respectively, when a $400-\mathrm{V}$ dc source is used. The THD of the line currents in this experiment is equal to $10.06 \%$ and the peak to peak torque ripple is equal to $1.700 \mathrm{~N} \cdot \mathrm{m}$. 
(a)

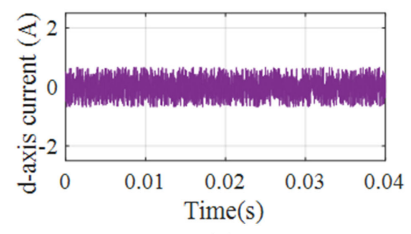

(c)

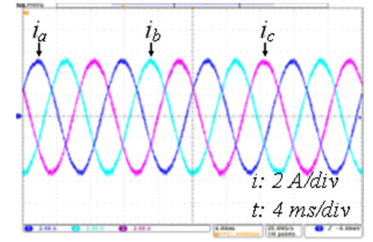

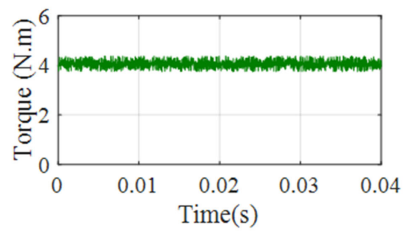

(b)

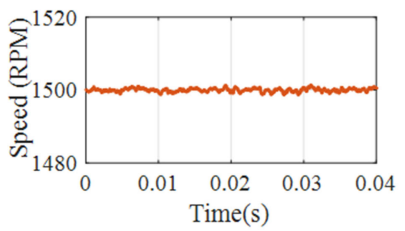

(d)
Fig. 17. Steady-state PMSM operation with the modified qZS network at $1500 \mathrm{r} / \mathrm{min}$ speed. (a) PMSM three-phase currents. (b) Delivered torque. (c) $d$-axis motor current. (d) Shaft speed.

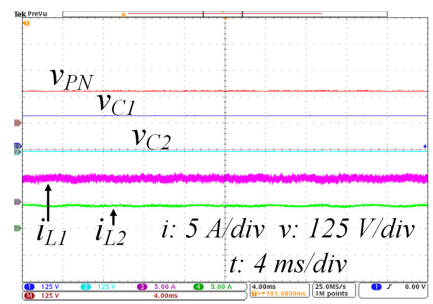

Fig. 18. Waveforms for qZS variables for the experiment of Fig. 17.

The waveforms in Fig. 17(a)-(d) show the measurement results for PMSM three-phase currents, developed torque, $d$-axis current, and shaft speed, respectively, when modified qZS network and the proposed control system are used. The THD of the PMSM phase currents in this condition is equal to $3.73 \%$. Similar to before, this shows a $6.33 \%$ reduction compared to the case with a constant dc source. The peak to peak delivered torque ripple in this condition is equal to $0.530 \mathrm{~N} \cdot \mathrm{m}$, which shows a $1.170 \mathrm{~N} \cdot \mathrm{m}$ reduction $(68.82 \%$ reduction) compared to the case with a constant dc source. Results of these two experiments further confirm the previous results about reducing the THD of motor currents and the delivered torque ripple.

Fig. 18 illustrates the waveforms for modified qZS network quantities for this experiment. This figure illustrates that the proposed MMPC controller for qZS effectively stabilizes the qZS control variables.

In the next experiment, the transient response of the proposed method to a reference speed change is evaluated. To perform this experiment, the speed reference is first stepped up from 1500 to $2500 \mathrm{r} / \mathrm{min}$ and then is stepped down from 2500 to $2000 \mathrm{r} / \mathrm{min}$, while the load torque has been kept constant at $4 \mathrm{~N} \cdot \mathrm{m}$. Fig. 19 illustrates the motor side results. The results of this experiment demonstrate the effectiveness of the proposed method for following the speed reference.

Fig. 20 illustrates measurements of modified qZS network variables for this experiment. As pictured, during this experiment, the proposed method adjusts the modified qZS output voltage to keep the torque ripple at minimum.

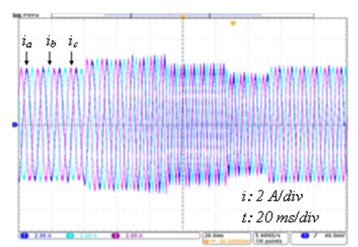

(a)

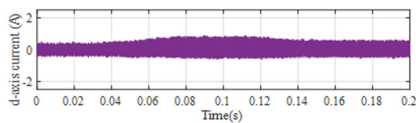

(c)

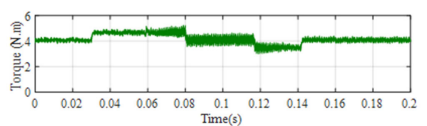

(b)

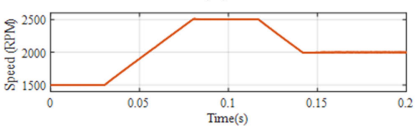

(d)
Fig. 19. Transient response of the PMSM using the proposed control system. (a) PMSM three-phase currents. (b) Delivered torque. (c) $d$-axis motor current. (d) Shaft speed.

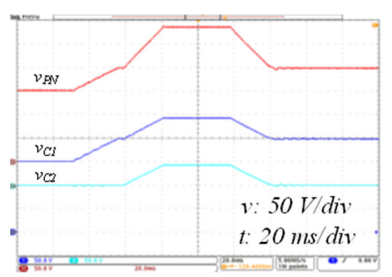

(a)

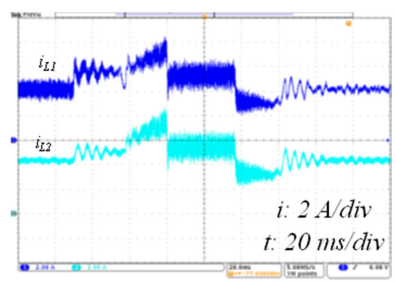

(b)
Fig. 20. Transient response of the modified qZS network to speed change of the motor. (a) Capacitor voltages $v_{\mathrm{PN}}, v_{C 1}$, and $v_{C 2}$. (b) inductor currents $i_{L 1}$ and $i_{L 2}$.

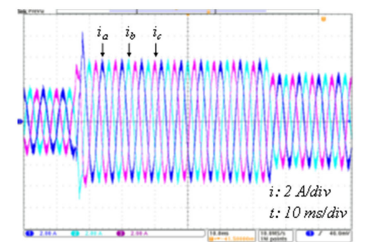

(a)

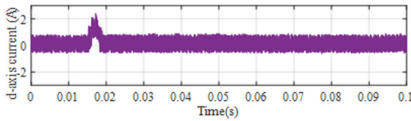

(c)

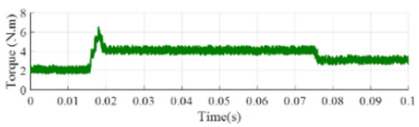

(b)

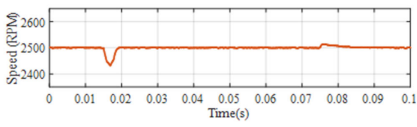

(d)
Fig. 21. Transient response of the PMSM variables to load torque change. (a) PMSM three-phase currents. (b) Delivered torque. (c) $d$-axis motor current. (d) Shaft speed.

In the next experiment, the transient response of the proposed method to a load torque change is evaluated. To perform this experiment, the load torque is first stepped up from 2 to $4 \mathrm{~N} \cdot \mathrm{m}$ and subsequently is stepped down from 4 to $3 \mathrm{~N} \cdot \mathrm{m}$, while the shaft speed is kept constant at $2500 \mathrm{r} / \mathrm{min}$. Fig. 21 illustrates the motor side results. This figure demonstrates that the proposed control system effectively responds to changes in the load torque.

Fig. 22 illustrates the waveforms for modified qZS network quantities for this experiment. This figure demonstrates that in case of a load torque transient, the proposed controller for modified qZS network effectively regulates the current of the inductors to comply with the new load torque requirement of the PMSM. 


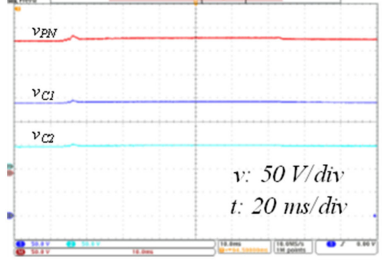

(a)

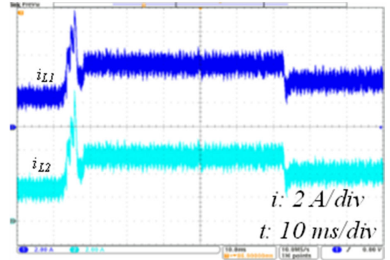

(b)
Fig. 22. Transient response of the modified qZS network to load torque change. (a) Capacitor voltages $v_{\mathrm{PN}}, v_{C 1}$, and $v_{C 2}$. (b) Inductor currents $i_{L 1}$ and $i_{L 2}$.

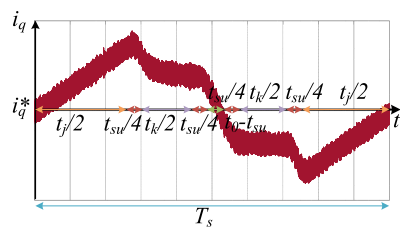

(a)

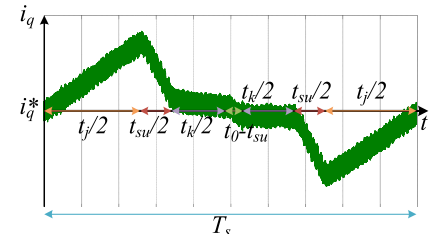

(b)
Fig. 23. Experimental $q$-axis current trajectories. (a) Conventional SVM switching technique. (b) Proposed SVM switching technique.

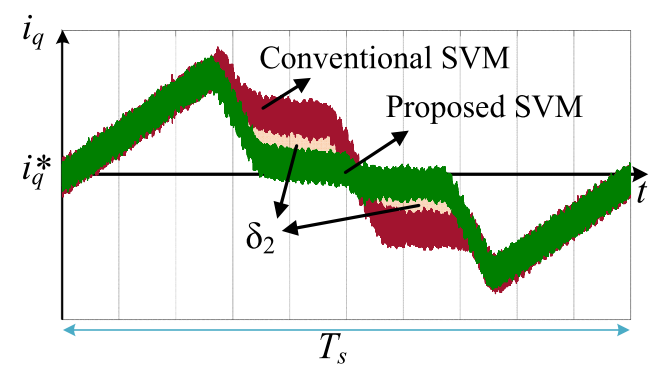

Fig. 24. Comparison of $q$-axis current trajectories for the switching techniques in Fig. 23.

In the final experiment, the effect of the proposed SVM switching technique for switching-based torque reduction is compared to the conventional SVM. In this experiment, the motor is operating at $2500 \mathrm{r} / \mathrm{min}$, while the shaft is delivering $4 \mathrm{~N} \cdot \mathrm{m}$ torque. Fig. 23 compares the $q$-axis current of the motor when the two switching techniques have been used for generating inverter switching signals.

Fig. 24 depicts the two waveforms in Fig. 23 superimposed. According to this figure, the switching-based torque ripple using the proposed method is $2 \delta_{2}$ less than the switching-based torque ripple of the conventional SVM for an inverter with a Z-source network.

\section{CONCLUSION}

This work presented a torque ripple minimization scheme for a modified qZS-based PMSM drive system to reduce the PMSM torque ripples while satisfying other control objectives during motor operation. The proposed voltage-based torque ripple reduction technique provided an optimal voltage profile reference for the modified qZS network to reduce PMSM torque ripples. The demonstrated MMPC method could effectively follow the provided reference. The proposed switching-based torque rip- ple reduction method further reduced the torque ripple at any given voltage reference point by altering the switching sequence selection scheme. It is also worth mentioning that the shut-off network added to the conventional qZS network in this paper imposes extra power losses to the whole system. On the other hand, the torque ripple minimization method optimizes the input voltage of the inverter, which leads to lower applied voltage on the inverter switches compared to the conventional qZS inverter and subsequently decreases the power loss of the inverter. Hence, it is hard to determine whether the proposed method would increase the efficiency or decrease it without comparing the switching losses in whole system for different operating conditions. Nevertheless, the efficiency examination of the method is complicated and will be studied in future work. Furthermore, in the proposed method, the input voltage of the inverter is optimized to achieve lower output torque, which inevitably reduces the dynamics of the system as well. The provided experimental results confirmed that the proposed technique can effectively reduce the torque ripples of the PMSM at various operating conditions. The results also confirmed that the proposed technique operates effectively during dynamic changes applied to PMSM speed or load. The ability of the proposed switching based method for further reducing the torque ripple was also illustrated using experimental results.

\section{REFERENCES}

[1] F. Z. Peng, "Z-source inverter," in Proc. Conf. Record IEEE Ind. Appl. Conf. 37th IAS Annu. Meeting, 2002, vol. 2, pp. 775-781.

[2] F. Z. Peng, "Z-source inverter," IEEE Trans. Ind. Appl., vol. 39, no. 2, pp. 504-510, Mar./Apr. 2003.

[3] Y. Liu, H. Abu-Rub, and B. Ge, "Z-source/quasi-Z-source inverters: Derived networks, modulations, controls, and emerging applications to photovoltaic conversion," IEEE Ind. Electron. Mag., vol. 8, no. 4, pp. 32-44, Dec. 2014

[4] F. Z. Peng, Y. Xiaoming, F. Xupeng, and Q. Zhaoming, "Z-source inverter for adjustable speed drives," IEEE Power Electron. Lett., vol. 1, no. 2, pp. 33-35, Jun. 2003.

[5] P. Fang Zheng et al., "Z-source inverter for motor drives," IEEE Trans. Power Electron., vol. 20, no. 4, pp. 857-863, Jul. 2005.

[6] A. Battiston, E. H. Miliani, J. P. Martin, B. Nahid-Mobarakeh, S. Pierfederici, and F. Meibody-Tabar, "A control strategy for electric traction systems using a PM-motor fed by a bidirectional Z-source inverter," IEEE Trans. Veh. Technol., vol. 63, no. 9, pp. 4178-4191, Nov. 2014.

[7] X. Li, C. Xia, Y. Cao, W. Chen, and T. Shi, "Commutation torque ripple reduction strategy of Z-source inverter fed brushless DC motor," IEEE Trans. Power Electron., vol. 31, no. 11, pp. 7677-7690, Nov. 2016.

[8] K. Xia, J. Lu, C. Bi, Y. Tan, and B. Dong, "Dynamic commutation torqueripple reduction for brushless DC motor based on quasi-Z-source net," IET Electric Power Appl., vol. 10, pp. 819-826, 2016.

[9] G. Feng, C. Lai, and N. C. Kar, "A closed-loop fuzzy-logic-based current controller for PMSM torque ripple minimization using the magnitude of speed harmonic as the feedback control signal," IEEE Trans. Ind. Electron., vol. 64, no. 4, pp. 2642-2653, Apr. 2017.

[10] Z. Zeng, C. Zhu, X. Jin, W. Shi, and R. Zhao, "Hybrid space vector modulation strategy for torque ripple minimization in three-phase fourswitch inverter-fed PMSM drives," IEEE Trans. Ind. Electron., vol. 64, no. 3, pp. 2122-2134, Mar. 2017.

[11] M. H. B. Nozadian, E. Babaei, S. H. Hosseini, and E. S. Asl, "Steady-state analysis and design considerations of high voltage gain switched Z-source inverter with continuous input current," IEEE Trans. Ind. Electron., vol. 64, no. 7, pp. 5342-5350, Jul. 2017.

[12] A. Ayad, P. Karamanakos, and R. Kennel, "Direct model predictive current control strategy of quasi-Z-source inverters," IEEE Trans. Power Electron., vol. 32, no. 7, pp. 5786-5801, Jul. 2017. 
[13] E. Babaei and E. S. Asl, "High-voltage gain half-bridge Z-source inverter with low-voltage stress on capacitors," IEEE Trans. Ind. Electron., vol. 64, no. 1, pp. 191-197, Jan. 2017.

[14] M. Aleenejad, H. Mahmoudi, P. Moamaei, and R. Ahmadi, "A faulttolerant strategy based on fundamental phase shift compensation for three phase multilevel converters with quasi-Z-source networks," in Proc. IEEE Power Energy Conf. Illinois, 2016, pp. 1-6.

[15] M. Aleenejad, H. Mahmoudi, and R. Ahmadi, "A fault-tolerant strategy based on fundamental phase-shift compensation for three-phase multilevel converters with quasi-Z-source networks with discontinuous input current," IEEE Trans. Power Electron., vol. 31, no. 11, pp. 7480-7488, Nov. 2016

[16] Y. Liu, H. Abu-Rub, and B. Ge, "Front-end isolated quasi-Z-source DCDC converter modules in series for high-power photovoltaic systems-part I: Configuration, operation, and evaluation," IEEE Trans. Ind. Electron., vol. 64, no. 1, pp. 347-358, Jan. 2017.

[17] Y. Liu, H. Abu-Rub, and B. Ge, "Front-end isolated quasi-Z-source DCDC converter modules in series for high-power photovoltaic systems-part II: Control, dynamic model, and downscaled verification," IEEE Trans. Ind. Electron., vol. 64, no. 1, pp. 359-368, Jan. 2017.

[18] J. V, J. Kotturu, and S. Das, "Enhanced-boost quasi-Z-source inverters with two switched impedance network," IEEE Trans. Ind. Electron., vol. 64, no. 9, pp. 6885-6897, Sep. 2017.

[19] S. Bayhan, M. Trabelsi, H. Abu-Rub, and M. Malinowski, "Finite-controlset model-predictive control for a quasi-Z-source four-leg inverter under unbalanced load condition," IEEE Trans. Ind. Electron., vol. 64, no. 4, pp. 2560-2569, Apr. 2017.

[20] S. Bayhan, H. Abu-Rub, and R. S. Balog, "Model predictive control of quasi-Z-source four-leg inverter," IEEE Trans. Ind. Electron., vol. 63, no. 7, pp. 4506-4516, Jul. 2016.

[21] H. Mahmoudi, M. Aleenejad, and R. Ahmadi, "A new multiobjective modulated model predictive control method with adaptive objective prioritization," IEEE Trans. Ind. Appl., vol. 53, no. 2, pp. 1188-1199, Mar./Apr. 2017.

[22] X. Zhang, B. Hou, and Y. Mei, "Deadbeat predictive current control of permanent-magnet synchronous motors with stator current and disturbance observer," IEEE Trans. Power Electron., vol. 32, no. 5, pp. 38183834, May 2017.

[23] H. Mahmoudi, M. Aleenejad, P. Moamaei, and R. Ahmadi, "Fuzzy adjustment of weighting factor in model predictive control of permanent magnet synchronous machines using current membership functions," in Proc. IEEE Power Energy Conf. Illinois, 2016, pp. 1-5.

[24] M. Aleenejad, H. Mahmoudi, and R. Ahmadi, "Unbalanced space vector modulation with fundamental phase shift compensation for faulty multilevel converters," IEEE Trans. Power Electron., vol. 31, no. 10, pp. 72247233, Oct. 2016

[25] B. Ge et al., "Current ripple damping control to minimize impedance network for single-phase quasi-Z source inverter system," IEEE Trans. Ind. Informat., vol. 12, no. 3, pp. 1043-1054, Jun. 2016.

[26] H. Mahmoudi, M. Aleenejad, and R. Ahmadi, "Modulated model predictive control of modular multilevel converters in VSC-HVDC systems," IEEE Trans. Power Del., 2017, doi: 10.1109/TPWRD.2017.2727478.
[27] Y. Liu, B. Ge, H. Abu-Rub, and F. Z. Peng, "Overview of space vector modulations for three-phase Z-source/quasi-Z-source inverters," IEEE Trans. Power Electron., vol. 29, no. 4, pp. 2098-2108, Apr. 2014.

[28] E. R. C. d. Silva, E. C. D. Santos, and B. Jacobina, "Pulsewidth modulation strategies," IEEE Ind. Electron. Mag., vol. 5, no. 2, pp. 37-45, Jun. 2011.

[29] P. Cortes, J. Rodriguez, C. Silva, and A. Flores, "Delay compensation in model predictive current control of a three-phase inverter," IEEE Trans. Ind. Electron., vol. 59, no. 2, pp. 1323-1325, Feb. 2012.

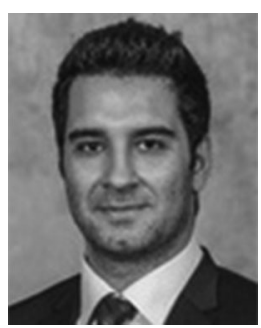

Hamid Mahmoudi was born in 1989. He received the B.Sc. degree in electrical engineering from the Noshirvani University of Technology, Mazandaran, Iran, in 2011, and the M.Sc. degree in electrical engineering from the Iran University of Science and Technology, Tehran, Iran, in 2014. He is currently working toward the Ph.D. degree in electrical engineering with the University of Kansas, Lawrence, KS, USA.

His research interests include design and control of power electronic converters, motor drives, multilevel converters, and solar energy systems.

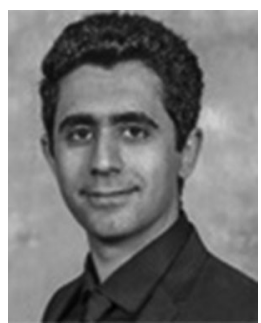

Mohsen Aleenejad (S'15-M'17) received the B.S. and M.S. degrees in electrical engineering from the AmirKabir University of Technology (Tehran Polytechnic), Tehran, Iran, in 2010, and the University of Tehran, Tehran, in 2013, respectively. He received the Ph.D. degree from The University of Kansas, Lawrence, KS, USA, in 2017.

$\mathrm{He}$ is currently a Postdoctoral Researcher with the Electrical and Computer Engineering Department, New York University, New York, NY, USA. His research interests include power electronics and its applications in power grid systems.

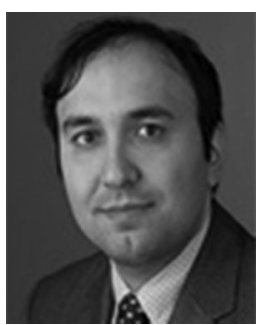

Reza Ahmadi (M'13) received the B.S. degree in electrical engineering from the Iran University of Science and Technology, Tehran, Iran, in 2009, and the $\mathrm{Ph} . \mathrm{D}$. degree in electrical engineering from the Missouri University of Science and Technology, Rolla, MO, USA, in 2013.

$\mathrm{He}$ is currently an Assistant Professor of electrical and computer engineering with the University of Kansas, Lawrence, KS, USA. His research interests include modeling, design, and control of power electronic converters, electric-drive vehicles, and solar energy systems. 